Loyalitas Kreativitas

Aldi Masyarakat Kreatif
P-ISSN 2722-2101, E-ISSN 2722-4201

Program Studi Ekonomi Manajemen Universitas Pamulang

Jurnal LOKABMAS Kreatif Vol.01, No.03,Hal.37-43

Email:jurnalkreatif.manajemen@gmail.com

\title{
PRODUKSI BUNGA HIAS DENGAN BAHAN KERTAS BEKAS DALAM MENCIPTAKAN PELUANG USAHA YANG LEBIH BERNILAI EKONOMIS
}

\author{
Lismiatun, Fadillah, ElaHulasoh, Abdul Azis, Vidya Amalia Rismanty \\ Dosen Ekonomi Fakultas Ekonomi Universitas Pamulang \\ Email : dosen01460@unpam.ac.id, dosen02197@unpam.ac.id. \\ dosen01910@unpam.ac.id dosen02241@unpam.ac.id,dosen02270@unpam.ac.id
}

\begin{abstract}
ABSTRAK
Tujuan dari Kegiatan Pengabdian Kepada Masyarakat adalah untuk melaksanakan salah satu Tridharma Perguruan Tinggi. Selain itu diharapkan dengan pengabdian kepada masyarakat tersebut keberadaan perguruan tinggi dapat memberikan kontribusi besar kepada pengembangan dan penerapan keilmuan kepada masyarakat.

Metode kegiatan yang digunakan adalah kita mendatangi sekolah PKBM Negeri 26 Bintaro yang beralamat Jl. Bintaro Permai III/30B, Kel. Bintaro, Kec. Pesanggrahan, Kota Administrasi Jakarta Selatan dan memberikan pelatihan disana pada tanggal 17-19 Oktober 2019. Pelatihan ini bertujuan agar siswa dan siswi yang bersekolah di PKBM Negeri 26 Bintaro khususnya pada program PKBM dapat meningkatkan kreatifitas dan inovasi memanfaatkan bahan kertas bekas yang diolah menjadi karya yang bernilai lebih serta melatih jiwa kewirausahaan para siswa-siswi.

Hasil pengabdian masyarakat yang diperoleh adalah bertambahnya keilmuan bagi Para Peserta (Siswa/siswi) PKBM Negeri 26 Bintaroagar mereka memiliki pandangan yang baik tentang pentingnya meningkatkan kreatifitas dan inovasi serta jiwa kewirausahaan atau entrepreneuragar mereka menjadi generasi penerus bangsa, menjadi SDM yang berkualitas untuk memasuki dunia kerja karena betapa pentingnya meningkatkan kualitas diri mereka untuk menghadapi persaingan dalam dunia kerja.

Ilmu yang diperoleh pada Pengabdian Masyarakat kali ini diharapkan mampu memberikan semangat baru bagi kita dalam menyampaikan materi dan motivasi serta berkontribusi bagi generasi muda, baik dilingkungan sekolah, kampus, masyarakat dan keluarga.
\end{abstract}

Keywords: produksi, ekonomi, entrepreneur

\begin{abstract}
ABSTRAC
The purpose of Community Service Activities is to carry out one of the Tridharma Perguruan Tinggi. In addition, it is expected that through community service, the existence of higher education institutions can make a major contribution to the development and application of knowledge to the community.

The method of activity used is that we go to the shcool PKBM Negeri 26 Bintaro having the address at Jl. Bintaro Permai III / 30B, Bintaro, Kec. Pesanggrahan, City Administration of South Jakarta and gave training there on 17-19 October 2019. This training aims to make students and students who attend PKBM Negeri 26 Bintaro especially in the PKBM program be able to increase creativity and innovation utilizing used paper materials that are processed into works that more value and train the entrepreneurial spirit of the students.
\end{abstract}




\section{Loyalitas Kreativitas \\ Aldi Masyarakat Kreatif}

P-ISSN 2722-2101, E-ISSN 2722-4201

Program Studi Ekonomi Manajemen Universitas Pamulang

Jurnal LOKABMAS Kreatif Vol.01, No.03,Hal.37-43

Email:jurnalkreatif.manajemen@gmail.com

The results of community service obtained are increased knowledge for Participants (Students) of the school PKBM Negeri 26 Bintaro so that they have a good view of the importance of increasing creativity and innovation as well as their entrepreneurial spirit or entrepreneurship to become the next generation of the nation, becoming qualified human resources to enter the world work because of how important it is to improve the quality of themselves to face competition in the world of work.

The knowledge gained in Community Service this time is expected to be able to provide new enthusiasm for us in delivering material and motivation and contribute to the young generation, both in schools, colleges, communities and families.

Keywords: production, economic, entrepreneur

\section{PENDAHULUAN}

Menanamkan jiwa kewirausahaan kepada siswa/i dapat menjadi salah satu solusi untuk mengurangi jumlah angka pegangguran terutama dari lulusan siswa/i jenjang pendidikan Sekolah Kejuruan Menengah. Kreativitas dan ketrampilan para peserta didik dalam menghasilkan produk kerajinan, produk budidaya ataupun produk pengolahan saat ini sudah mulai dilatih dan diajarkan sejak di Sekolah Menengah Kejuruan.

Kewirausahaan merupakan sebuah proses mengidentifikasi, memodifikasi, mengembangkan suatu produk baru, metode baru dengan cara-cara inovasi atau terobosan baru yang belum pernah di lakukan oleh orang lain sebelumnya baik cara produksi maupun pemasarannya untuk mendapatkan keuntungan atau laba. Menurut Keputusan Menteri Koperasi dan Pembinaan Pengusaha Kecil Nomor 961/KEP/M/XI/1995, kewirausahaan adalah semangat, sikap, perilaku dan kemampuan seseorang dalam menanggani usaha atau kegiatan yang mengarah pada upaya mencari, menciptakan serta menerapkan cara kerja, teknologi dan produk baru dengan meningkatkan efisiensi dalam rangka memberikan pelayanan yang lebih baik dan atau memperoleh keuntungan yang lebih besar.

Sangat pentingnya memberikan dukungan kepada para siswa/i untuk memiliki kompetensi dalam kewirausahaan yang lebih ditekankan pada contoh nyata cara-cara berwirausaha dengan memanfaatkan peluang pasar saat ini dengan strategi menyusun perencanaan, memproduksi, mengemas serta memasarkan dengan cara yang sangat sederhana.

Oleh karena itu sangat besar harapan kegiatan seperti ini mendapat dukungan baik oleh seluruh pihak baik itu pihak sekolah, orang tua, masyarakat serta akademisi dalam melihat talenta-talenta generasi muda saat ini yang sangat kreatif dan inovatif. Sehingga para siswa/i tersebut nantinya sudah memiliki pondasi jiwa wirausahawan yang mampu menjadi SDM yang unggul dalam menciptakan peluang usaha.

\section{RUMUSAN MASALAH}

Dengan mempertimbangkan latar belakang yang telah dijelaskan diatas kami berinisiatif untuk membentuk pengabdian masyarakat bagi siswa dan siswi yang bersekolah di PKBM Negeri 26 Bintaro khususnya dalam program pelatihan agar dapat Produksi Bunga Hias Dengan Bahan Kertas Bekas Menciptakan Peluang Usaha Yang Bernilai Ekonomis.

Setelah mengetahui strategi dan tata cara pelatihan menciptakan dan mengolah limbah kertas bekas yang diolah menjadi bunga hias yang memiliki nilai ekonomis serta melatih jiwa enterprenuer 
Loyalitas Kreativitas

Aldi Masyarakat Kreatif
P-ISSN 2722-2101, E-ISSN 2722-4201

Program Studi Ekonomi Manajemen Universitas

Pamulang

Jurnal LOKABMAS Kreatif Vol.01, No.03,Hal.37-43

Email:jurnalkreatif.manajemen@gmail.com para siswa/i agar memiliki jiwa kompetensi, merangsang ide dan kreatifitas yang lebih baik di PKBM Negeri 26 Bintaro, diharapkan para siswa di PKBM Negeri 26 Bintarodalam mengembangkan cara-cara, metode dan inovasi yang lebih kreatif dan menarik.

\section{TUJUAN PELAKSANAAN}

1. Memberikan pengetahuan kepada siswa dan siswi PKBM Negeri 26 Bintaro mengenai cara menumbuhkan jiwa kewirausahaan.

2. Memberikan pengetahuan kepada siswa dan siswi PKBM Negeri 26 Bintaro mengenai peluang usaha dari bahan bekas kertas secara online.

3. Memberikan gambaran dan pengetahuan kepada siswa dan siswi PKBM Negeri 26 Bintaro mengenai cara menciptakan atau mengolah limbah kertas bekas menjadi nilai produk jual ekonomis.

\section{TINJAUAN PUSTAKA}

\section{Pengertian Ekonomi}

Ekonomi atau economic dalam banyak referensi ekonomi berasal dari bahasa Yunani yaitu dari kata Oikos atau Oiku yang berarti keluarga dan kata Nomos yang berarti aturan. Sehingga jika digabungkan maka pengertian ekonomi adalah aturan dalam rumah tangga.

Menurut P.A Samuelson (Putong, 2013:3) pengertian ekonomi adalah suatu studi bagiamana orangorang dan masyarakat membuat pilihan, dengan atau tanpa menggunakan uang, dengan menggunakan sumber-sumber daya alam yang terbatas tetapi dapat dipergunakan dalam berbagai cara untuk menghasilkan berbagai jenis barang dan jasa serta mendistribusikan untuk keperluan konsumsi, sekarang dan dimasa mendatang, kepada berbagai orang atau golongan masyarakat.
Secara umum, ekonomi dapat diartikan sebagai bidang yang terkait dengan aturan kehidupan rumah tangga dalam meningkatkan kesejahteraan serta menaikkan taraf hidup manusia dengan segala keterbatasan sumber daya alam sehingga timbullah kegiatan ekonomi yang diatur dengan cara berpikir atau pola pikir dan cara bertindak yang disebut ekonomis atau menurut prinsip ekonomi, manfaat mempelajari ilmu ekonomi antara lain :

1. Mengetahui permintaan pasar atau pelanggan

2. Menciptakan peluang usaha baru atas produk yang kita kreasikan

3. Meningkatkan pemahaman potensi dan kebijakan ekonomi

4. Memahami keterbatasan kita dalam menentukan pilihan tujuan dalam perencanaan ekonomi dimasa depan

\section{Pengertian Produksi}

$\begin{array}{rr}\text { Dalam } & \text { kehidupan } \\ \text { bermasyarakat guna memenuhi }\end{array}$ kebutuhan hidup manusia yang beraneka ragam, manusia memerlukan barang dan jasa yang tidak dapat dihasilkan sendiri, suatu kegiatan yang menghasilkan barang dan jasa disebut produksi.

Menurut Sofjan Assauri (2016:153) produksi adalah kegiatan yang melibatkan tenaga manusia, bahan serta peralatan untuk menghasilkan produk yang berguna.

Secara umum proses produksi dapat diartikan sebagai kegiatan atau proses merubah suatu bahan mentah menjadi bahan siap pakai/konsumsi, bentuk, wujud dengan meningkatkan atau menambah manfaat suatu barang atau jasa untuk memenuhi kebutuhan manusia.

Faktor-faktor yang dapat dilakukan untuk mencapai produksi yang optimal antara lain yaitu : 
Loyalitas Kreativitas

Aldi Masyarakat Kreatif
P-ISSN 2722-2101, E-ISSN 2722-4201

Program Studi Ekonomi Manajemen Universitas

Pamulang

Jurnal LOKABMAS Kreatif Vol.01, No.03,Hal.37-43

Email:jurnalkreatif.manajemen@gmail.com
1. Ketersediaan bahan dasar yang akan di produksi

2. Ketersediaan kapasitas alat bantu baik mesin, gunting, atk dll

3. Ketersediaan tenaga kerja atau sumber daya manusia

4. Prediksi besarnya permintaan akan hasil produksi

5. Tersedianya faktor-faktor produksi lainnya yang mendukung

\section{Pengertian Peluang Usaha}

Peluang usaha adalah sebuah kreasi yang berdiri sendiri, lahir dari pemikiran sendiri, extraordinary, serta kemandirian. Dalam menjalankan usaha pada wirausahawan harus memiliki pemikiran kreatif dan inovatif untuk mendapatkan hasil yang maksimal agar dapat meminimalisir kendala atau hambatan dalam menjalankan usahanya.

A. Sumber Peluang Baru

1) Cita-cita

Peluang dapat timbul dari cita-cita diri kita sendiri.

2) Riset atau survei pasar

Melakukan tanya jawab dengan konsumen

\section{3) Tekanan}

Dengan adanya tekanan terhadap seseorang baik internal ataupun eksternal akan melahirkan banyak ide atau gagasan

4) Minat atau kecenderungan pasar Mengamati kebutuhan konsumen dipasar dapat menciptakan peluang pasar

5) Inovasi baru

Adanya kebutuhan akan memunculkan gagasan untuk menciptakan produk baru hadir di masyarakat

6) Pelengkap dari produk yang sudah ada Sebuah produk dapat memberikan peluang usaha dengan membuat produk-produk yang melengkapi
7) Moment atau peristiwa yang digemari

Menurut Robbin dan Coulter peluang usaha adalah merupakan sebuah proses yang melibatkan individu atau kelompok yang menggunakan usaha dan sarana tertentu untuk menciptakan suatu nilai tumbuh guna memenuhi sebuah kebutuhan tanpa memperhatikan seumber daya yang digunakan.

Oleh karena itu sebagai calon wirausahawan sangat penting dalam memperhatikan faktor-faktor pendukung ataupun penghambat serta pandai dalam melihat peluang pasar yang ada. Menciptakan suatu produk yang berbeda, unik dan memiliki nilai estetika yang berbeda dari produk yang sudah beredar dipasar sebelumnya akan menjadikan produk memiliki nilai yang tinggi. Pemasaran atau promosi yang sederhanadengan memanfaatkan media sosial yang ada akan membantu memperkenalkan kepada masyarakat dengan efektif dan efisien.

\section{METODE PELAKSANAAN}

Kegiatan yang dilakukan lebih kepada interaktif kepada pada siswa/i dengan memberikan arahan, bimbingan, tanya jawab bagaimana cara-cara yang paling mudah untuk dilakukan para siswa/i dalam pengambilan keputusan.

Sebelum kegiatan berlangsung tim pengabdian melakukan tahap sosialisasi terlebih dahulu yaitu melakukan silaturahmi dengan Ketua Yayasan, menyampaikan maksud dan tujuan pengabdian ini, sekaligus untuk menjalin kerjasama serta menentukan jadwal kegiatan pengabdian. Pelaksana kegiatan pengabdian pada masyarakat adalah Dosen Universitas Pamulang Fakultas Ekonomi Program Studi Manajemen sebanyak 5 orang dosen dan diikuti oleh para siswa/i dengan jumlah sebanyak 40 orang siswa serta guru-guru pendamping sebanyak 5 orang. 
Loyalitas Kreativitas

Aldi Masyarakat Kreatif
P-ISSN 2722-2101, E-ISSN 2722-4201

Program Studi Ekonomi Manajemen Universitas

Pamulang

Jurnal LOKABMAS Kreatif Vol.01, No.03,Hal.37-43

Email:jurnalkreatif.manajemen@gmail.com
Kegiatan pengabdian kepada masyarakat dilakukan dengan metode sebagai berikut:

1. Identifikasi masalah yang dilakukan sebagai langkah awal untuk merumuskan apa saja yang akan dijadikan bahan untuk perancangan sistem dan materi pelatihan dalam kegiatan pengabdian ini.

2. Melakukan survei lapangan ke Sekolah PKBM Negeri 26 Bintaro sebagai tempat dilaksanakannya kegiatan. Kemudian melakukan proses wawancara dan diskusi dengan pihak sekolah untuk identifikasi permasalahan yang ada dalam lingkungan siswa intra sekolah.

3. Kontribusi pengusul dalam proses pengabdian dengan melakukan penelitian pustaka untuk acuan materi yang digunakan selama kegiatan pengabdian.

Pelatihan ini bertujuan agar siswa dan siswi yang bersekolah di PKBM Negeri 26 Bintaro khususnya pada program PKBM dapat menumbuhkan jiwa kewirausahaan dalam hal produksi bunga hias dengan bahan kertas bekas dalam menciptakan peluang usaha yang bernilai ekonomis.

\section{HASIL DAN PEMBAHASAN}

Berdasarkan wawancara, tanya jawab dan pengamatan langsung selama kegiatan berlangsung, kegiatan pengabdian pada masyarakat ini memberikan hasil sebagai berikut :

a. Memberikan pengetahuan kepada siswa dan siswi mengenai cara menumbuhkan jiwa kewirausahaan

b. Memberikan pengetahuan kepada siswa dan siswi mengenai peluang usaha dari bahan bekas kertas

c. Memberikan gambaran dan pengetahuan kepada siswa dan siswi PKBM Negeri 26 Bintaro mengenai cara memciptakan atau mengolah limbah kertas bekas menjadi nilai produk jual ekonomis.

Beberapa faktor yang mendukung terlaksananya kegiatan pengabdian pada masyarakat ini adalah besarnya minat dan antusiasme peserta selama kegiatan, sehingga kegiatan berlangsung dengan lancar dan efektif. Sedangkan faktor penghambatnya adalah keterbatasan waktu pelatihan dan fasilitas peralatan yang masih minim.

\section{KESIMPULAN DAN SARAN Kesimpulan}

Dari kegiatan pengabdian pada masyarakat ini dapat disimpulkan bahwa:

1. Pengetahuan dan pemahaman siswa dan siswi PKBM Negeri 26 Bintaro tentang produksi bunga hias dengan bahan kertas bekas dalam menciptakan peluang usaha yang bernilai ekonomis menjadi meningkat.

2. Semakin meningkatnya ide dan kreatifitas bunga hias dalam menciptakan peluang usaha yang bernilai ekonomis.

\section{Saran}

Mengingat besarnya manfaat kegiatan pengabdian pada masyarakat ini, maka selanjutnya perlu:

1. Mengadakan sosialisasi dan pelatihan serupa pada siswa sekolah lain di Kecamatan yang lain, dengan materi yangserupa.

2. Adanya kesinambungan program pasca kegiatan pengabdian ini sehingga para siswa benar-benar dapat memproduksi bunga hias dengan bahan kertas bekas dalam menciptakan peluang usaha yang bernilai ekonomis 
Loyalitas Kreativitas

Aldi Masyarakat Kreatif
P-ISSN 2722-2101, E-ISSN 2722-4201

Program Studi Ekonomi Manajemen Universitas

Pamulang

Jurnal LOKABMAS Kreatif Vol.01, No.03,Hal.37-43

Email:jurnalkreatif.manajemen@gmail.com

\section{DAFTAR PUSTAKA}

Assauri, Sofjan, Manajemen Produksi dan Operasi, PT. Grafindo Persada, 2016 hlm. 153

Elburdah, R. P., \& Oktrima, B. (2020). PENGARUH COMMUNITY OF PRACTICE PADA IMPLEMENTASI KNOWLEDGE MANAGEMENT PADA KANTOR KELURAHAN REMPOA. JURNAL LOKABMAS KREATIF, 1(2), 11-15.

Iskandar, Putong, Economics Pengantar Mikro \& Makro Full Edition, Mitra Wacana Media, Jakarta, 2010, hlm. 1

Pasaribu, V. L. D., Susanti, F., \& Hartuti, E. T. K. (2019). Memotivasi Siswa dan Siswi SMK Letris Indonesia di Dalam Menentukan Pilihan Untuk Melanjutkan Pendidikan Atau Bekerja Setelah Lulus Sekolah. Jurnal Pengabdian Dharma Laksana, 1(2), 161-172.

Pasaribu, V. L. D., Elburdah, R. P., Sudarso, E., \& Fauziah, G. (2020). PENGGUNAAN MANAJEMEN WAKTU TERHADAP PENINGKATAN PRESTASI BELAJAR DI SMP ARAISIYAH. Jurnal ABDIMAS Tri Dharma Manajemen, 1(1).

Pasaribu, V. L. D., Agrasadya, A., Shabrina, N., \& Krisnaldy, K. (2020). MENJADI ENTERPRENEUR MUDA YANG MEMILIKI JIWA LEADERSHIP UNTUK MENGHADAPI MASA DEPAN. Abdi Laksana, 1(1).

Pasaribu, V. L. D., Sulaiman, S., Sutiman, S., Thaharudin, T., \& Purnomo, B. Y. (2020). PENGENALAN LETAK POSYANDU TERDEKAT DIKELURAHAN PISANGAN DENGAN MANAJEMEN PEMASARAN REVOLUSI 4.0 UNTUK MENINGKATKAN PENGETAHUAN MASYARAKAT LETAK DAN FUNGSI POSYANDU TERDEKAT PADA KELURAHAN PISANGAN. DEDIKASI PKM, 1(1), 105-110.

Priadi, A., Pasaribu, V. L. D., Virby, S., Sairin, S., \& Wardani, W. G. (2020). PENGUATAN EKONOMI KREATIF BERBASIS SUMBER DAYA DESA DIKELURAHAN REMPOA. Abdi Laksana, 1(3), 356-358.
Samuelson, P.A, Putong, Macroekonomi, Erlangga, Jakarta, 2013 hlm.3

Suryana, Kewirausahaan Full Edision, Salemba Empat, Jakarta, 2013

Sumber Dari Internet:

https://www.dosenpendidikan.co.id/peluan g-usaha dilihat pada tanggal 15 Oktober 2019 pukul 16.10 WIB.

https://www.academia.edu/7878221/_EKO 3046 Pengertian Ekonomi Menurut Par a_Ahli dilihat pada tanggal 15 Oktober 2019 pukul 16.30 WIB.

https://www.zonareferensi.com/pengertiankewirausahaan/ dilihat pada tanggal 16 Oktober 2019pukul 10.10 WIB http://www.sarjanaku.com/2012/12/penger tian-produksi-luas-menurut-para.html? $\mathrm{m}=1$ dilihat pada tanggal 16 Oktober 2019 pukul 10.45 WIB

\section{DOKUMENTASI FOTO KEGIATAN}

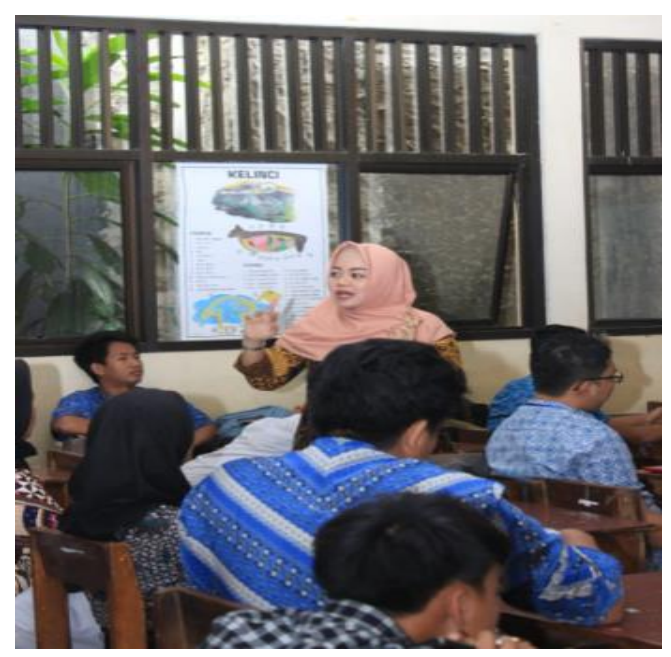


Loyalitas Kreativitas

Abdi Masyarakat Kreatif
P-ISSN 2722-2101, E-ISSN 2722-4201

Program Studi Ekonomi Manajemen Universitas

Pamulang

Jurnal LOKABMAS Kreatif Vol.01, No.03,Hal.37-43

Email:jurnalkreatif.manajemen@gmail.com
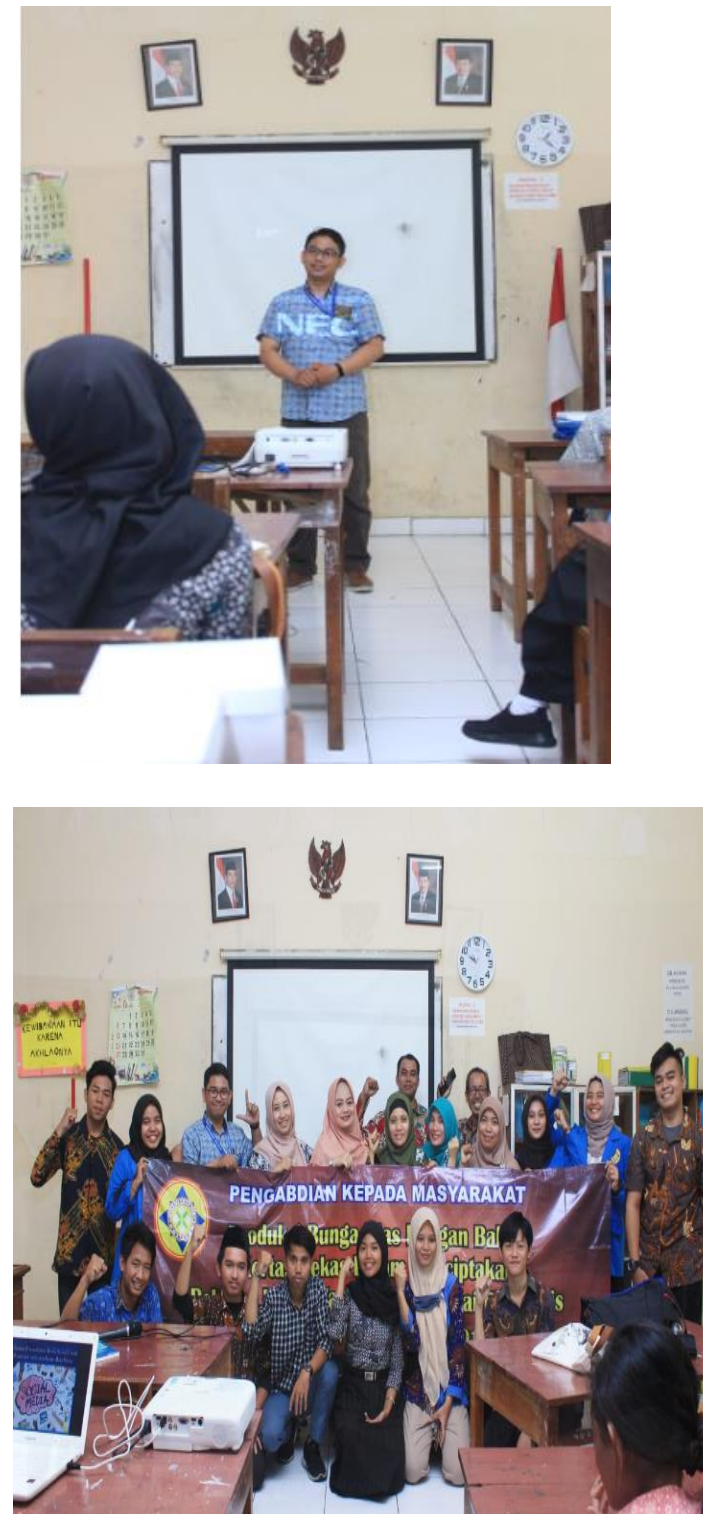